\title{
Strategic decision-making under ambiguity: a new problem space and a proposed optimization approach
}

\author{
Richard J. Arend ${ }^{1}$ (D)
}

Received: 15 May 2020/ Accepted: 15 October 2020/Published online: 2 November 2020

(C) The Author(s) 2020

\begin{abstract}
The existence of ambiguity presents a challenge to decision-makers as it eliminates the ability to apply standard optimization approaches, such as those based on calculating the objective expected values of alternative actions. In reality, ambiguity arises in most strategically important decisions in some form because of the genuine limits on the decision-maker's rationality and on the information available about the alternatives and the future. To address that reality, we define such problems as strategic decision-making under ambiguity where choices over resource investments must be made in competitive environments where possible outcomes and their payoffs are known ex ante, but the probabilities of such outcomes are unknowable ex ante. We outline a multi-step, logical approach for addressing such problems in theory with the goal of providing an improved basis for practical decisions that should increase organizational performance.
\end{abstract}

Keywords Ambiguity - Strategic decision-making · Efficient frontier ·

Managerial incentives

JEL classification B21 $\cdot$ D81 - G11 $\cdot$ M55

\section{Introduction}

Most research in management focuses on decision-making in risky contexts, given the ease of modeling and experimenting on expected utility maximization (e.g., Malecka 2020; Starmer 2000). However, ambiguity poses a more important type of

Richard J. Arend

richard.j.arend@gmail.com

1 School of Business, College of Management and Human Service, University of Southern Maine, PO Box 9300, Portland, ME 04104, USA 
uncertainty context facing managers making strategic decisions (Paraschiv and Shyti 2016). Where with risk the probabilities of the focal outcome possibilities are known ex ante, with ambiguity they are not, and that makes objective optimization over choices impossible. Thus, we propose a new approach for dealing with strategic decision-making under ambiguity (SDMUA).

Current SDMUA approaches are severely limited. Either they do not move away from a behavioral perspective that simply describes what managers do when confronted by ambiguity in a lab or in a unique case setting, or they do not actually capture ambiguity instead reducing it to risk by invoking subjective beliefs over unknowable expected outcomes. And, none yet extend the DMUA to strategic competitive issues. That leaves a gap for a new SDMUA approach that retains the effects of ambiguity and provides a normative path to better decision-making.

Better dealing with ambiguity is an important and widely-applicable concern. Most daily decisions involve incomplete knowledge, and specifically the kind that generates uncertainty over outcome probabilities, better known as ambiguity (e.g., Peysakovich and Karmarkar 2016). Such decisions include everything from choosing a dish from a menu to choosing a medical or retirement plan to contemplating the value of a stock (e.g., Jia et al. 2020; Peysakovich and Naecker 2017). Such decisions also confront managers facing decisions that can affect firm performance, like hiring, tactical policy setting and target valuation (e.g., Cinelli 2020; Pike et al. 2018; Peysakovich and Karmarkar 2016).

As many scholars astutely have noted, “...empirical evidence (e.g., Becker and Brownson 1964; Curley and Yates 1985; Gardenfors and Sahlin 1982; Yates and Zukowski 1976) has shown that ambiguity affects judgments and choices and should not, therefore, be ignored" (Einhorn and Hogarth 1986: S227). For example, Hahn et al. (2014) find that ambiguity significantly affects decision-makers' proclivity to choose more radical alternatives. These decisions do not involve risk; rather, they are often described as involving Ellsbergian ambiguity (1961) — a form of Knightian (1921). Ambiguity is a concept that decision-makers must address, and one that can be used to create strategic value (e.g., Petkova et al. 2014; Srivastava 2015). The main reason is that ambiguity prohibits the calculation of first-best solutions to those decisions in reality (e.g., Elbanna and Child 2007); the optimal choices for such decisions cannot be identified in the standard way ex ante. But, at present, there is no accepted, standard approach to dealing with SDMUA. There are descriptions of what humans do. There are mathematical models that reduce ambiguity to the risk and determine what humans should do based on their subjective beliefs. But, there is no prescription for what to do when ambiguity remains ambiguity. That is why it is important to provide an approach that improves decision-making in situations where managers are forced to commit to resource investments while facing important, indeterminate, uninsurable, competitive futures that will affect organizational performance.

To fill that gap, we focus on what a logical, rational, objective, properlyincentivized manager should decide when confronted by ambiguity. As such, our approach is necessarily theoretical; it is provided at a general problem level. That means it is not immediately applicable in a real world because, at that level, the specifics of the problem, of the ambiguity and of the manager's incentive contract, 
are all likely to affect how our approach would be implemented on-sight. While decision-making is most often not conducted in a rational, objective or general way, we nevertheless do see value in analyzing it as such. We follow the rich tradition in the theoretical literature for conducting such analysis because we expect it to be of value not only as a benchmark for decision-makers to draw upon but also because we expect that for strategic decisions, such greater rationality, objectivity and efforts will actually be present. And, because of the theoretical nature of our approach, we can draw on several powerful tools in our solution to SDMUA, including game theory and contract design. Game theory is relevant because these problems deal with interdependent payoffs and rivals. Incentive contract design is relevant because we focus on choices made by a firm manager, who is expected to rationally behave based on how they are compensated in ways that align with the owners' interests. To our knowledge, based on keyword searches across business journals, no papers have combined all of the tools we have in one approach, let alone to address a SDMUA problem. So, this is new and speaks to the leverage that current economic concepts can generate when packaged together in an appropriate context.

Our intended contribution threefold: first, we describe SDMUA as a new branch of SDM. Second, we outline our theoretical second-best solution approach as a new combination of existing economic tools. Third, we offer a set of new prescriptions and predictions based on the use of that approach.

We argue for our new SDMUA approach in the remainder of the paper. We review the research to put our contribution in perspective. We specify the example we use to capture SDMUA. Then, we provide our new resolution to the challenge of SDMUA-one that is theoretically implementable. Based on that, we propose several performance-related relationships, and discuss the implications our approach has for academics, practitioners and policy-makers.

\section{Literature review}

Ambiguity has many definitions in the literature, so there is a need to be clear on which one is used (as we are in the next section). Most of the ambiguity research has been conducted at the level of individual decision-making, and mostly in a behavior way, and even more specifically, in terms of its avoidance. However, there exists some research relating to how to deal with it in important decisions and what the costs are associated with its effects. It can affect strategic decision-making, but there is insufficient work on that topic at present. With that summary, we proceed in reviewing the relevant literature in more detail now.

Perhaps ironically, one problem with making progress in addressing ambiguity is the ambiguity involved in that term. There exist significant imprecision and disagreement over the concept of ambiguity in the literature. Ambiguity has been conceptualized as a specific type of informational context facing a decision-maker. The nature of that context has been characterized in several ways. The context has most often been characterized in terms of the quantity and determinacy of information available (Forbes 2007). The context has been characterized in terms of the heterogeneity of the underlying available data, the imprecision of that data, and 
the lack of consensus over its applicability. Further, the context has been characterized by the lack of quality and frequency in that underlying data, its noise, its relevance, its type, its reliability, and the credibility of its source. The context has been characterized by the extent of expert disagreement over that underlying data, and the potential for multiple interpretations of it (Eichberger and Guerdjikova 2013; Pich et al. 2002). And, the context has been characterized in terms of unknown outcomes (Camerer and Weber 1992), in terms of the unknowns about the processes that generate them. Conceptualizing ambiguity in this way also entails assessing the range of unknown information defining it (Lant and Mezias 1990), its level of uniqueness (Ellsberg 1961), and the nature of how the ambiguity was transmitted to decision-maker.

Ambiguity has also been studied in terms of individual-level factors affecting SDMUA. For example, it has been studied in terms of the decision-maker's strength of prior beliefs over the probabilities of the decision's alternative outcomes, the decision-maker's level of experience dealing with similar decisions, and the decision-maker's strategic motive in becoming involved (e.g., Sillince et al. 2012). It has been studied in terms of the decision-maker's stance as reactive or proactive, protective, invited, adaptive, or something else. It has been studied by analyzing the source of the decision-maker's strategic concern regarding the ambiguity (Bajtelsmit et al. 2015) in terms of whether it is based on the lack of control or on some fear or on the maximum downside. It has been studied in terms of the effects on the capacity of the decision-maker to process the choices, based on the information load, complexity, numerousity, diversity, and interdependencies involved in the decision.

Finally, ambiguity has also been studied in terms of its possible ways strategic effects and ways to address them. In terms of how its effects can be addressed, the literature has considered several possible ways to mitigate the downsides (CerreiaVioglio et al. 2013; Gollier 2014), such as choosing a maximin alternative or building some insurance or some exit option. Research has involved assessing the costs to reduce the ambiguity (Rindova et al. 2010) and to what extent it can be reduced over a set time period. The literature has also attempted to identify the range and variance of the possible outcomes involved in the ambiguous decision and its interventions (Machina 2014). In terms of attempting to clarify ambiguity's possible strategic effects, studies have taken several paths. One path consists of distinguishing the level of surprise potentially involved in the ambiguous situation, and specifically whether any outcomes involve violations of laws or norms. Another path consists of identifying the level of analysis of the ambiguity affects (Miller 1993) in terms of the potential strategic consequences at the national, industry, firm, and project levels. Such consequences assess the types of externalities potentially involved, in addition to establishing whether the ambiguity is interconnected with other choices and to what extent (Langley et al. 1995).

The ambiguity over what ambiguity means is much lower in the behavioral economics literature related to decision-making. Work in the theory of evidence (Shafer 1976), fuzzy sets (Zadeh 1978), ambiguous probabilities (Marschak 1975), and probability ranges (Curley and Yates 1985; Wallsten et al. 1983) all relate to the type of ambiguity we use here and as defined in gambles over colored balls in urns, 
as described by Ellsberg $(1961,1963)$. For example, from Ellsberg's work, there has emerged strong agreement over the observed and experimentally-verified individual-level bias termed ambiguity aversion (e.g., Budescu et al. 2002; Curley and Yates 1989; Gilboa and Schmeidler 1989; Heath and Tversky 1991; Schmeidler 1989). That bias describes an overweighting low likelihoods and an underweighting high likelihoods of possible outcomes (Paraschiv and Shyti 2016). There is also high consistency in terms of how DMUA research has mathematically explained ambiguity aversion. That research has mostly invoked models based on prospect theory-as-behavioral-predictions over how people make risky choices based on subjective beliefs and utilities. Such models include the decision-maker's utility function combined with her probability weighting function over possible outcomes (e.g., Kahneman and Tversky 1979; Tversky and Kahneman 1992). However, such models struggle to explain observed behaviors in SDMUA-like settings (e.g., Li et al. 2017).

Ambiguity is a recognized, and often explicitly described, factor that makes strategic decisions even more challenging. It appears as one main reason that incomplete contracts exist in transaction cost economics (Tadelis 2002). It appears as one main reason why waiting to invest is important in real options theory (McGrath 1999). And, it appears as one main reason for the popularity of approaches like fast-fail, rapid-prototype, and focused experimentation when businesses enter new frontiers (Newman 2009).

\section{This model of ambiguity in a strategic decision}

To illustrate how our new approach to SDMUA works, we first need to describe an example decision. And, to do that, we need to define our main concepts, list our assumptions and then detail the model of that decision facing the firm manager.

\subsection{Main definitions}

We define ambiguity as follows: ambiguity exists when the set of future possible outcomes is known, as is the set of actions possible to take, as are the payoffs for each action in each outcome, but the (absolute) probabilities of those outcomes are all unknowable prior to having to make the decision. This definition is consistent with the standard Ellsbergian (1961) version used throughout the behavioral research stream.

We define strategic decisions in terms of their competitive implications (e.g., Leiblein et al. 2018). Because they involve significant and irreversible resource commitments (Ghemawat 1991), such decisions are taken seriously and are supposed to be approached with rational, objective analysis. Consistent with that characterization in the literature, we define strategic decisions as choices over resource investments involving significant competitive performance. Given that rivals can directly affect firm profitability, and indirectly affect their financing, the inclusion of competitive issues is paramount. 
We believe that SDMUA exists but it has not been explored properly. Past research has ignored addressing at least one of its three main conditions. For clarity, we argue our definition of SDMUA as composed of three conditions: First, the core ambiguity is inescapable. The ambiguity must be addressed in the decision. It cannot simply be reduced ex ante or ex tempore. It is economically infeasible to simply wait out the clock for the ambiguity to resolve. It is also economically infeasible to experiment or otherwise search for information to resolve the ambiguity prior to having to make the focal choice. The decision-maker is forced to make irreversible commitments for the firm given the unknowable probabilities over possible outcomes that exist. Second, the focal interdependent parties involved all experience the ambiguity. Relative performance effects are a central focus in strategy. Managers are often judged by how well their investments do with reference to those of rivals. SDMUA involves accounting for rival choices under ambiguity as well, as these decisions explicitly include competitive influences on payoffs (e.g., Dyer and Singh 1998; Porter 1980; Zajac and Olsen 1993). Third, parties exist that are separate and different from the focal decision-maker, parties who recognize that the ambiguity exists for the decision-maker. Those parties include the interdependent rivals alluded to above, as well as the principals (e.g., the owners, investors, partners, and other stakeholders) of the firm who assess and reward the manager-agent decision-maker who is choosing investments for that organization.

With these conditions, SDMUA diverges from past DMUA research in that the focus is not solely upon individual behavior in isolation but instead is about managerial behavior in an organizational and competitive context.

\subsection{Main assumptions}

In our model, we take a specific, real-world perspective - that of a firm's manager. We assume that this decision-maker's goal is to identify the best possible choice for her firm based on the information available to her about the ambiguity, the probabilities, the payoffs, the incentive system, and the rivals. She acts as the agent to the firm owners who are the principals. In other words, we are not trying to solve the principals' problem in dealing with ambiguity (because they are likely more diversified over the issue), nor are we trying to add a principal-agent issue to what is already a complex problem. We are simply taking the problem from a standard point of view of an important decision-maker-that of the manager.

As our illustrative example problem, we assume that the manager faces a standard investment choice decision; so, this is not a narrow phenomenon of focus. The twist here is that ambiguity is explicitly an issue in our model, where it is most often ignored (or converted into risk) in other studies of what are common choice problems that involve incomplete knowledge (Peysakovich and Karmarkar 2016).

We assume that the manager is a rational, self-interested agent whose behavior is predictably influenced by her incentive scheme at the firm where she has the responsibility for making strategic decisions, for example, over investment choices. Given she is rational, we assume she has the ability to apply standard business tools, in this case, to mitigate the effects of the ambiguity and attempt to identify better 
choices. Further, we assume she knows the incentive scheme she faces, and that she is capable of looking ahead to what could occur in the future and what the rewards would be, and then working backwards to making a suitable choice now.

Given this is a normative analysis, we assume that there are no information asymmetries between the owners and the manager, that the owners have greater opportunity costs, and that the manager is more efficient at addressing firm-level decisions, which is why she has been delegated to do so. Further, we assume that the firm owners who employ her know this as well, in addition to the owners and managers of rival firms and other payoff-interdependent entities (and vice versa).

We assume that ambiguity presents itself in the following way: the probability of one of the main possible outcomes - that affects the payoffs of the set of choices-is unknowable prior to the decision. That primary outcome could represent the focal firm's future bankruptcy, a collapsed nation-state's political future, the scope of impending industry regulation, or the winner of a competitive standards war. The focal probability is economically irreducible to the decision-maker and all others involved in the strategic outcomes and, hence, is unknowable. And, because one probability is unknowable, then the probabilities of all other possible outcomes are also unknowable, which meets our definition of ambiguity.

That being the case, we still assume there remain many important knowns available to the decision-maker. Specifically, the manager can predict what all of the alternative possible outcomes are as well as the payoffs arising from them. We imagine that firm managers who find themselves navigating markets involving rapidly-evolving technologies, unstable economies, volatile regulatory environments, unpredictable rivalry, and fluid demand are still expected to have the ability to understand what could happen regardless of whether they can estimate the associated probabilities of happening. Further, we also assume that the manager can estimate the conditional probabilities of all other outcomes-i.e., given the main outcome with an unknowable probability does not occur, the manager can estimate the probabilities of the alternative outcomes occurring. For example, this is a problem where one could know the probability of the stock price of the nonbankrupt firm rising to a specific level. (Again, this is consistent with the Ellsbergian definition of ambiguity we adopt.)

More formally, we label the primary outcome's unknown probability as ' $p$ ', so that the complementary unknown probability of it not occurring is: ' $1-p$ '. When the primary outcome does not occur, the set of alternative outcomes is known. We denote the conditional probabilities of these alternative outcomes as $a, b, c \ldots$, where they are normalized to sum to one. We can then calculate the probability of alternative outcome ' $\mathrm{A}$ ' occurring as ' $a \cdot(1-p)$ '.

We also assume that the focal unknown probability is not bounded by a small range-to make the ambiguity issue non-trivial. Let $p$ represent that primary outcome's unknown probability, such that $1>p>0$, and cannot include the endpoints-i.e., $p \neq 1$ and $p \neq 0$. This is a minimally-restrictive assumption that rules out any possibility that the ambiguity can be summarily ignored.

To remove other trivialities, we further assume that the manager confronts an investment choice set that is sufficiently diverse as to involve trade-offs. For example, an investment choice that pays off more under one outcome pays off less 
than an alternative investment under a different outcome. Specifically, there exists no one choice that simply dominates all others across all possible outcomes; each choice is not dominated simply by any other.

In terms of timing, we assume that the decision has to be made by a specific time, $T$. Only after $T$ do the outcomes of the investment portfolio choice become known and the gross payoffs can be realized. The net payoffs are those gross payoffs less the costs of that portfolio investment. Those gross payoffs may be affected by the choices of rival firm managers. We refer to those net payoffs as simply the payoffs henceforth, just as in game theory, where such payoffs are the table cell values in the normal form representation. And, just as in those games, the goal is to maximize the payoffs.

Figure 1 illustrates the tree-branch like model of the core of our generic SDMUA investment portfolio problem. This type of model remains consistent with the Ellsberg urn depiction of ambiguity, where some conditional probabilities are known but the primary outcome probability is not, where all possible outcomes are known, and where the net payoffs for each of those possible outcomes is also known.

\subsection{Modeling the choice problem under ambiguity}

To summarize the core of the SDMUA problem at this point, the decision-maker faces a set of possible irreversible resource investments that pay off differently in a future that entails several possible outcomes, where, because at least one outcome has an unknowable probability of occurring, all have unknowable probabilities. The decision-maker is a manager-agent, making decisions in an organizational and in a competitive context, where the principals and rival managers know of, or face, the same decision that includes the same ambiguity. And, this is a problem without an obvious path to optimization. Recall that if this primary probability is unknown then there is no way to calculate an expected value of any investment choice to compare it to other choices because at least one value in the calculation remains unknown. And, without an ability to compare investment choices, then no first-best solution is possible to calculate. The decision-maker is left confused.

To maximize the payoff in an interdependent setting, the manager has to compare payoffs in each interdependent interaction. The simplest way to visualize this is as a normal form game where the interactions are the cells (i.e., the intersection of each row and column action choice in the table of possible actions by the players). Each cell contains a specific sub-set of the full investment choice set, where the sub-sets are mutually-exclusive and collectively-exhaustive. The full SDMUA then entails finding not only the best investment within each cell to fill out the game table, but it also entails identifying the Nash equilibrium choice for the competitive game as a whole.

Finally, it is important to explain that alternative ways to characterize ambiguity in such a problem are unattractive. The characterization where the unknowable outcome's payoff can be anything theoretically, from negative infinity to positive infinity, is unattractive because then there really is no optimization or even nontrivial choice ordering to be done. A random choice is as good as any choice, as any 


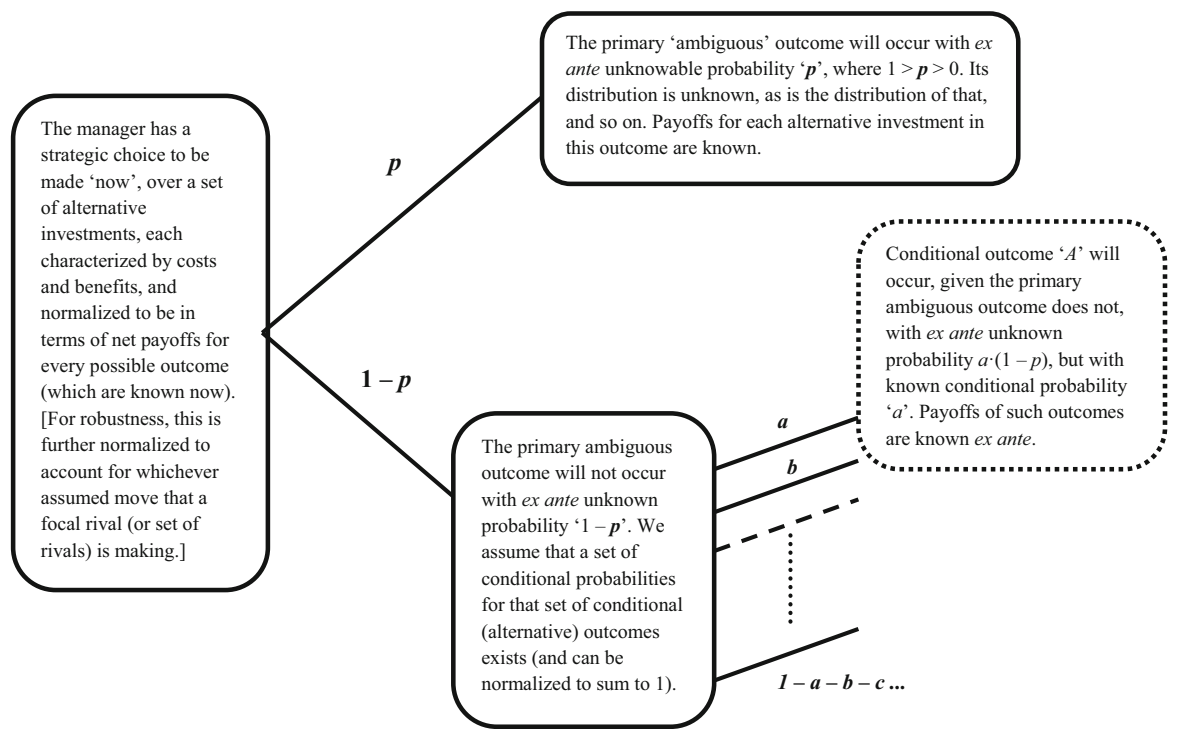

Fig. 1 Decision-making-under-ambiguity STEP 1A-the use of conditional probabilities to calculate conditional expected payoffs

choice could end up with an infinitely high or low payoff, and the decision problem becomes trivial. And, the characterization where the outcome is unknowable implies not only the unknowable probability but also an unknowable payoff and ends in the same triviality. The Ellsbergian characterization we use is the only characterization that generates a non-trivial problem.

\section{A new approach to addressing SDMUA}

Figure 2 is a flowchart depicting our new approach to the SDMUA problem. The manager is given the set of possible investment choices structured into subsets of choices, with each subset being defined in a row or a column of a normal form competitive game. It is a simultaneous-move game, given our definition of $T$ and, without loss of generality, it is played against one rival firm's manager. An irreducible ambiguity exists, denoted by ' $p$ '. The decision-making manager knows the incentive system that the firm owners are applying to influence her investment decision.

We summarize the approach first and then provide details in the subsections that follow. The proposed approach begins with the manager trying to maximize the payoff in each cell of the game. The manager understands that she is choosing a specific action that defines a specific subset of the investment choices while her rival is also choosing a specific action. The first step in the approach involves constructing the efficiency frontier for the subset of investment choices in the cell. 
Proposed Manager's Strategic-Decision-Making-Under-Ambiguity Flowchart

Condition
Process Flow

start
Given full SDMUA information, where the within-cell subset of investment choices' conditional payoffs are calculable and the normal form competitive game table cells have been defined for the competitive interaction...

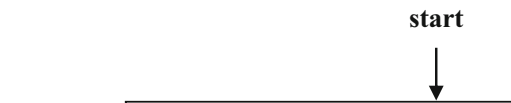

STEP 1a: Compute the conditional payoffs for the ambiguous event occurring ( $p)$, and not occurring $(1-p)$, for each possible within-cell choice for that specific cell.

STEP 1b: Construct the ' $p$ ' vs ' $1-p$ ' payoff
efficiency frontier across all within-cell
choices.
choices.

STEP 2: Use backward induction to identify the incentive reward based on the future SDMUA outcome to choose the intended best point along the efficiency frontier now. from principal about this SDMUA

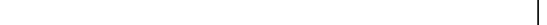

point along the efficiency frontier now.

Given the known incentive scheme
from the rival's principal about this
within-cell choices and their
conditional payoffs...

Given the assumed rationality and information available for the approach for all entities...
STEP 3a: Enter that point as the firm's 'chosen payoff' in the cell. Run the same analysis for the rival, and enter its payoff in the cell as well.

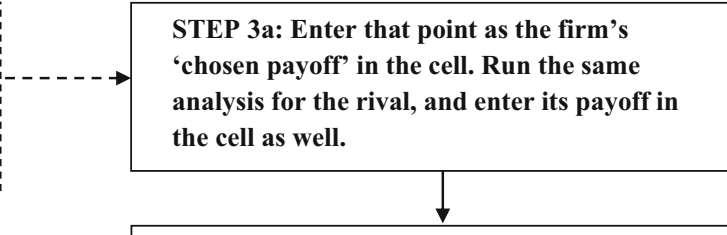

STEP 3b: REPEAT the previous steps for EACH different cell in the normal form tableof-cells.

STEP 3c: Compute the Nash Equilibrium for the normal form game, and select the best strategy (row/ column).

Fig. 2 Proposed manager's strategic-decision-making-under-ambiguity flowchart

This is accomplished by computing the conditional payoffs for each investment choice in the cell, and then plotting the ' $p$ ' versus ' $1-p$ ' points that can be used to calculate a continuous frontier made up of combinations of the investments. The second step in the approach involves choosing a point along that frontier that the principals direct from the incentive scheme they use to reward the manager; this is done through backward induction. The third step involves solving the full game that is made up of the computed information in the cells of the game. This involves: 
(i) entering that point as the chosen payoff in the cell for the manager, and then running the same analysis for the rival manager and entering its point in that cell as well; (ii) repeating all previous steps for the remainder of the cells for both the focal manager and the rival manager; and, (iii) then identifying the Nash equilibrium based on the full game. The approach is complete when the manager chooses the firm's Nash equilibrium strategy that also indicates the specific investment choice in that equilibrium cell.

\subsection{Determine the efficiency frontier of investment choices}

The first step is to identify the non-dominated investment choice combinations. That builds an efficiency frontier composed of a subset of the available investments. Visualizing that frontier entails plotting each investment's payoff when the primary outcome occurs (on the $y$-axis) relative to when it does not (on the $x$-axis). This step leverages the standard approach to the finance problem of determining an optimal risk-return investment portfolio. In finance, investments are reduced to their mean and variance of returns and plotted to identify a convex frontier of optimal investments that maximize returns-for-risks (Markowitz 1952). In our approach, we plot the alternative investment choices in terms of their returns when the primary outcome occurs against their returns when the primary outcome does not occur (see Fig. 3). This reduces a large set of information made up of the payoff profiles of the full set of available investments down into a visual, wide-ranging two-dimensional

Decision-Making-Under-Ambiguity’s Efficiency Frontier for Possible Investments

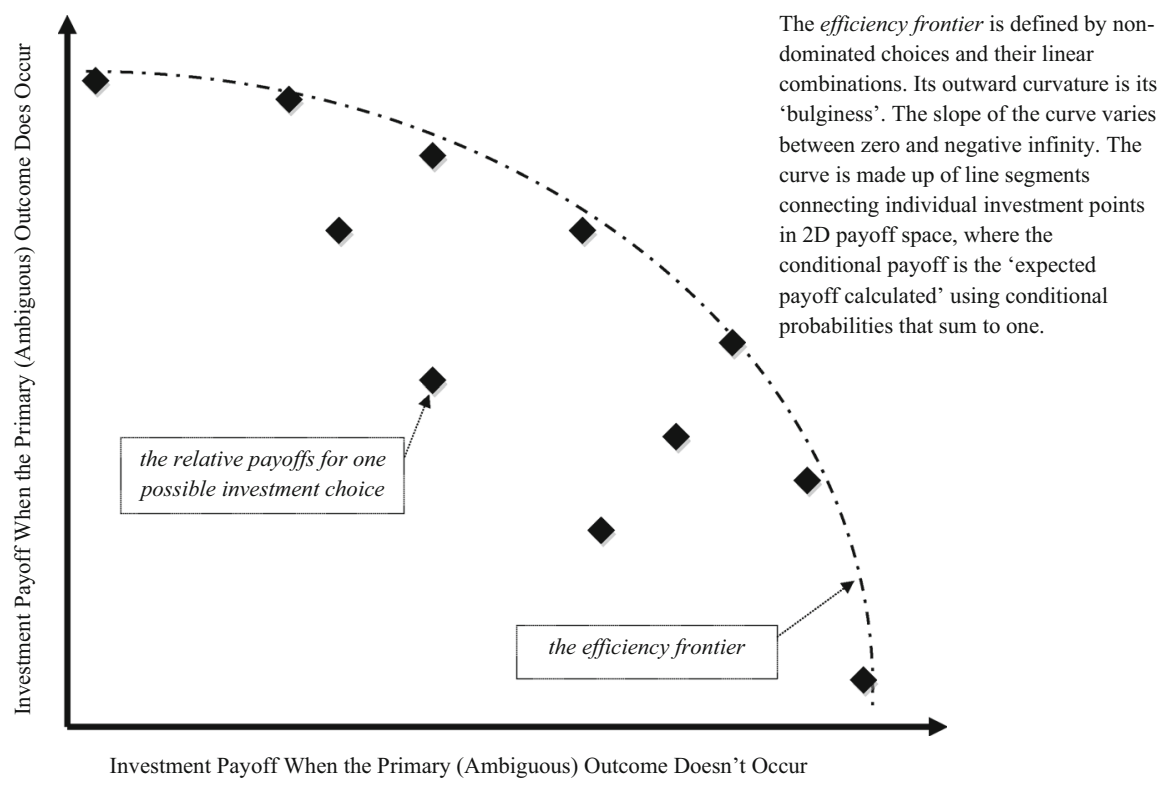

Fig. 3 Decision-making-under-ambiguity's efficiency frontier for possible investments 
representation of the problem. Recall that for the condition when the primary outcome does not occur, we assumed that we could compute the conditionally expected returns over the set of alternative outcomes in the standard manner used for risk-based expected valuation, weighing each outcome payoff by its normalized conditional probability (i.e., $a, b, c \ldots$ ) and summing. Plotting the investments' returns of the two complementary possible outcomes (i.e., ' $p$ ' and ' $1-p$ ') generates a convex frontier where, to gain more returns in the primary outcome, one has to give up some expected returns in the alternative outcomes, and vice versa. When the set of choices is finite, as we assume it is, then the frontier is filled in with linear combinations of the closest adjacent investment choices bracketing the gaps, which makes an outward curve from the straight line segments that meet at obtuse angles.

In this first step some optimizing work has been done, as a given subset of investment choices has been reduced to a more-attractive smaller subset that defines the efficiency frontier. But, that still does not provide the decision-maker with the one relatively best choice among this smaller set of efficient alternative investments in this game cell. The next step does that.

\subsection{Identify the ex post rewards and induce backwards}

The second step in our approach identifies the one relatively best choice along the frontier by specifying a function that exposes the optimal trade-off between the two complementary possible outcomes' payoffs. Without that function to maximize, there is no identification of the preferred choice to address the manager's SDMUA problem within each game cell. However, the manager should not just choose any function, given each such function would likely entail a very different ex post repercussion for her. For example, if the manager chose a point on an extreme of the frontier, then if she were unlucky, not only would her job likely be in peril, so might be the firm's future. Thus, a prudent and rational manager would look ahead to what could occur and what the rewards would be, and then work backwards to making a better choice now. For example, if the manager was most worried by the worst-case outcome in the future, a maximin function may be used to determine the optimal choice along the efficiency frontier now. Thus, based on that projected repercussion, we propose that the trick to resolving the problem is to consider applying backwards induction, to look at the decision-maker's situation after the ambiguity is resolved, and then work back to how that resolution could influence the choices now. Thus, the second step in our approach is for the manager to apply backwards induction on the incentive scheme she faces to identify the one point on the efficiency frontier that provides the best outcome for her and, as implied by the choice of that incentive scheme by the firm's principals, for the firm as well.

As an aside, this paper does not provide the recommendation for which incentive scheme that firm's principal should choose, given that would depend on many factors unique to firm, its principals, its context, and the focal decision itself. We leave such specific applications of our approach for future work. 


\subsection{Explicitly consider the main interdependencies}

With the completion of the second step that specified the preferred choice for the manager facing a SDMUA problem in each game cell, the only issue left is to consider explicitly the strategic interdependencies. The third step of our approach specifies how payoff interdependencies are handled. In this step, we consider explicitly the effects on the focal firm's payoffs of the rival manager's choices.

In reality, rivals matter for several reasons. Directly, they influence pricing and sales; they can also influence access to preferred players in the industry supply chain (e.g., through vertical foreclosure-Porter 1980). Besides affecting the absolute profitability that a firm realizes, rivals affect a firm's access to attractive financial support through the relative profitability that investors use to choose which firms to back. As such, accounting for rival moves is not simply a game theoretic issue-in that their choices affect a focal firm's payoffs in any period of a competition-it is also a very real issue to many stakeholders of that firm.

We draw upon game theory's analysis methods to account for payoff interdependencies. In the normal form representation, the interdependencies are indicated in each of the table's cells that specify the payoffs for the firms in each combination of their choices. This implies that the better choice for the manager and her firm will also depend on what choice the rival firm's manager makes. This means that steps one and two have to be completed for every major choice available to the manager and her rival to fill out all the information for the normal form game relevant to the SDMUA. Once the game's alternative choices and payoffs are defined, then the usual game theory logic can be applied to identify the Nash equilibrium or best available investment choice for each manager to make. That concludes our approach, an approach that applies three existing tools-the efficiency frontier, backwards induction and game theoretical analysis-in a novel way to address the general SDMUA problem a firm manager would face in choosing a 'best' investment option in a competitive context given incomplete information.

\section{Consequent prescriptions and predictions}

The logic behind our new approach suggests several ways to increase firm performance when SDMUA is an issue: First, from step one we know that a rational manager should construct an efficient frontier given a set of possible investment choices for the firm. More attractive frontiers - the ones indicating higher valuesare those that extend further out from the origin. When investment choices are not exogenously given, it is straightforward to prescribe trying to create investment choices that push the frontier out further. For example, the three points found on the two axes and at the intersection of the $45^{\circ}$ line extending from the origin should be pushed out by creating one investment that pays off highly only when the primary outcome occurs, one investment that pays out highly only when the primary outcome does not occur, and one that pays out highly when ' $p=1 / 2$ '. The first prediction then is that the firms that can create more such investments should perform relatively better than those that cannot. 
Second, from step two we know that it is likely some firms can gamble their way into a potential short-term advantage by taking an aggressive stance on investment choices. For example, we know that those firms betting it all on one outcome with a maximax attitude, if lucky, can gain an immediate advantage over firms taking a maximin approach. In markets characterized by pro-entrepreneurial factors (e.g., forgiving bankruptcy laws and possible first-mover advantages), we expect that aggressive firms (i.e., those choosing the maximax reward system) will attempt to enter those markets more when SDMUA problems arise, and that the ones which survive will have a temporary advantage from having guessed right. So, we prescribe, when possible, for the incumbent to 'take options' (e.g., have an expandable ownership stake) in such entrants to share in their good fortunes. When that is not possible, we advise purchasing complementary assets that a lucky entrant would need to monetize on its own investment choice. The second prediction is that the firms proactive enough to mitigate the effects of lucky new entrants (e.g., through investing in relevant options or complementary assets) should perform relatively better than those that do not.

Third, from step three we know that interdependencies will affect the optimal choice of investments. The practical advice is for principals to tailor their firms' reward systems to the interdependencies involved. This could be as simple as including a relative performance term in the reward along with an absolute performance term. The third prediction is that the firms that implement reward systems that explicitly account for interdependent payoff effects when their managers are confronted by SDMUA problems should perform relatively better than those that do not.

The fourth prediction arises from the combination of the three steps: We expect the firms - through their managers and principals - that more closely follow our new approach when confronted by SDMUA problems will perform better than those that do not.

\section{Discussion}

We have described a new type of problem - the SDMUA - and a new approach to solving such challenges in the DMUU literature. Ours is the first approach to not violate the assumption of ex ante unknowable outcome probabilities. It is the first approach to explicitly exploit conditional probabilities regarding what could occur if the focal outcome-the one generating the ambiguity-does not occur. It exploits those probabilities by applying the standard efficiency frontier tool to remove dominated alternatives. Ours is the first approach to explicitly consider decisionmaker incentives through backwards induction logic. It does so to identify the payoff-maximizing point on the efficiency frontier for the decision-maker. Ours is the first approach to explicitly account for competitive payoff interdependencies. It applies standard game-theoretic analysis to address interdependencies with payoffrelated effects of a rival's manager who is also making investment choices relating to the ambiguity. We suggest that the payoffs for each decision choice combination in the overall decision game need to be calculated to identify the Nash equilibrium. 
We also contribute to the literature with new prescriptions and predictions based on the three steps underlying our approach.

We proposed SDMUA as a new branch in the rich DMUA literature, a literature that is growing in importance for management for several reasons. First, it is a reality that organizations are more regularly facing problems that are both strategic and ambiguous. Second, the firms facing more of these problems are the firms that policy-makers are more interested in because those firms are innovating in new technologies, markets, and business models where such unknowable outcome probabilities are more likely to occur. Third, the presence of ambiguity in strategic decisions is growing. It is growing due to the added dynamics and complexities of the marketplace, the increasing velocities of competition and cooperation (e.g., Joseph and Gaba 2015), the rapid pace of technological and regulatory progress, the consistently unstable global landscape, and the often-lagging or non-existent regulatory regimes that all make strategic decisions and actions more challenging. In other words, our approach to addressing SDMUA is timely and has widening importance as a benchmark to practical application.

As such, we believe that it is not sufficient to continue to tolerate managers who rely on intuition, pattern-following, history-based-extrapolation, imitation, stalling, experimentation, or other simple behaviors when they address SDMUA. Such attempts to avoid it or reduce it simply are inferior and ineffective. However, up to this point, the literature has appeared hesitant and fragmented in building alternative approaches, with new ideas like anti-fragility (Taleb 2012) only trending as initial avenues to do so. Until now, there was no generalizable approach for managers to use to maximize value under ambiguous, competitive contexts. Certainly, there were many heuristics offered, including famous ones such as simple rules (Eisenhardt and Sull 2001), but none have had widespread empirical support for their superior long-term, general effectiveness based on how they handle true ambiguity specifically. This is problematic because human decision-makers are bad at dealing with ambiguity, whether as an umbrella concept or across many of its possible dimensions such as non-linearity and complexity, and are even worse when ambiguity is combined with having to deal with competition simultaneously (e.g., Dominiak and Duersch 2019). As such, we believe our SDMUA approach is a useful contribution.

To DMUA research, and to DM research more broadly, this paper also signifies a need to focus attention on building the bridge between the past studies of individual behaviors in relative isolation and the needed new studies of such behaviors in monitored, competitive, organizational contexts. Clarifying the translation from observations of willing participants in controlled lab gambles to noisy outcomes of incentivized managers making strategic investment choices that involve unknown probabilities, where multiple parties are interdependent, remains a challenge (e.g., Eason and Mazzei 2019). We simply need more work on how simplified lab studies inform complex field realities, and whether we are missing something crucial in the reductionism made to get to the lab level or the projections made to get to the field level. We expect more holistic issues to be involved, issues that are often addressed through heuristics by boundedly-rational managers, heuristics that may generate exploitable and harmful biases. We have advocated in our proposed approach to 
SDMUA the use of several small world tools to provide a structured, understandable, objective, and reliable process to deal with ambiguity, and argued for several consequent propositions. We are fully aware, though, that important things can be lost in translation (e.g., legal constraints that restrict compensation contract completeness), and so we advocate testing our approach and our propositions in the field.

Besides the aforementioned theoretical implications, our approach also has several practical implications, including those offered as prescriptions. One such further implication involves the importance of the structure of the management reward system on firm performance specifically in the context of ambiguity. We do not believe that incentive systems were ever designed with this ambiguity-related effect in mind. Given, in our analysis, it appears that luck, as the realization of choices made facing ex ante unknowable outcome probabilities, may play a greater part that previously admitted in explaining firm performance variance, the challenge to firm-owners-as-principals to design a robust incentive system for their managers facing SDMUA is not trivial. As such, we leave that for future work.

There are many other forms that future work on SDMUA can take. We suggest that, besides testing the approach proposed here, that case studies be conducted in various organizational contexts to determine what other approaches are being used, when, where, by whom, and why. Further, we advocate the study of the 'meta'decisions that organizations make: (i) about which contexts they wish their manager-decision-makers to be involved in, especially when there are contexts that involve ambiguity rather than versus risk; and, (ii) about how they perceive and even strategically generate ambiguities, such as causal ambiguity (Reed and DeFillippi 1990), for others.

Prior to providing some closing thoughts, we would be remiss if we did not consider in some further depth, the alternative approaches to SDMUA that we have mentioned in this paper. As we have alluded, currently, there are no alternative approaches to SDMUA problems that account for the three conditions of ex ante unknowable outcome probabilities, relevant managerial reward systems, and interdependent payoffs. That said, DMUA alternative approaches do exist. These can be divided into two camps:

The first camp is characterized by simple decision rules (Eisenhardt and Sull 2001), simple in that almost none are customized to decisions involving ambiguity specifically. These are simple rules that are agnostic about ambiguity-versus-risk, and include maximin, maximax, Hurwicz weighted maximin-maximax, and Savage minimax-regret (e.g., Su and Tung 2012). In management, this simple rules camp is more of a discussion over the amount of structure a firm needs in a less predictable world or over adaptive project management, rather than a direction over specifically how to make an investment decision (e.g., Davis et al. 2009; Lévárdy and Browning 2009). The one simple rule that does acknowledge ignorance over probabilities is the Laplace or uniform investment approach that simply assumes that each possible outcome is equally likely. The approaches in the first camp fall short for several reasons: There is nothing strategic about the approaches in this camp, as none consider interdependencies. Except for one rule, there is no customization for the ambiguity involved in the decision, and even for that exception there is an 
intuitive guess made about the distribution of the unknown probabilities. All of the rules produce a single investment choice, without giving any visualization of the sensitivities to proximate alternative choices. All of the rules implicitly assume that the firm's owners agree with the approach, and that the manager is properly incentivized to follow. And, none of the rules separates the identification of efficient investment trade-offs (our step one) from the choice among them (our step two), which makes the customization of the incentive system to specific possible rival moves (our step three) much more difficult to do and thus less likely to occur.

In contrast to the first camp, the second camp is defined by a focus on the effects of ambiguity in real decision-making behavior. The approach in the second camp is to model and describe individual-level DMUA behavior, most often by capturing observable ambiguity avoidance or decision-making inertia (Sautua 2017). This approach relates to two directions in the management literature - to understand how real managers deal with DMUA (e.g., by simplifying the problem-Hey et al. 2010) and to provide a way to mathematically model the effect of ambiguity on subjective beliefs over those objectively unknowable probabilities (Bryant 2014; Galaabaatar and Karni 2013). In the latter, based on observed individual-level DMUA behavior, scholars construct a function, or a process description, consistent with the consensus outcomes about how much participants pay to avoid the choices that include ambiguous probabilities. Such functions are constructed so that they become consistent with subjective expected utility (SEU) theory (Savage 1954) when the ambiguity reduces to zero. There are several functional forms put forth in the literature, with most appearing as variants to prospect theory (Kahneman and Tversky 1979; Tversky and Kahneman 1992). Such variants depict individuals placing subjective beliefs on outcomes, applying weights to those probabilities dependent on the belief levels and payoff outcomes involved, and then combining those weighted subjective probabilities with a utility function that is most often also weighted by contextual information, to get to their preferred choice. But, there are several problems that arise when applying models from this camp to real DMUA situations: First, there is no instruction about how to generate reasonable initial beliefs when ambiguity exists. Second, there is no direction on how to determine an accurate utility function for the manager, an agent who would have her own personal agenda, anchors, and ambiguity tolerance that may differ from those of the organization's owners or may be unknown to them. And third, there is no method given for determining an accurate probability weighting system that is likely to be used by this manager, let alone by rival managers, to influence or use these to the firm's advantage. Table 1 describes the main points of differentiation between our approach to the SDMUA problem and that of the second camp's approach to the DMUA problem.

In summary, we look forward to continued work in ambiguity to find better ways to understand and address it. For example, ambiguity research could be more explicitly linked to the literatures on information processing, communications, deception, signaling, and perception, to leverage related insights. Deeply considered, ambiguity even affects the very concept of knowledge itself, and of science-asprediction, given that we can only know something when we can form a justified true belief over it—something that ambiguity prevents. Thus, addressing ambiguity 
Table 1 Comparison of approaches to decision-making under ambiguity

\begin{tabular}{|c|c|c|}
\hline $\begin{array}{l}\text { Approach } \\
\text { characteristic }\end{array}$ & Prospect theory-based approach & Proposed 3-step approach \\
\hline Temporal focus & Ex ante, forward-looking & Ex post, with backward induction \\
\hline Prediction & $\begin{array}{l}\text { Subjective prediction of ambiguous } \\
\text { outcome, weighted for probability level, } \\
\text { outcome level, ... }\end{array}$ & No prediction of ambiguous outcome \\
\hline $\begin{array}{l}\text { Optimal } \\
\text { investment } \\
\text { choice }\end{array}$ & Calculated as one 'point' & $\begin{array}{l}\text { Visualized as an efficiency frontier from } \\
\text { which to choose a point dependent on } \\
\text { firm's reward system (wider, more } \\
\text { holistic view) }\end{array}$ \\
\hline $\begin{array}{l}\text { Heterogeneity } \\
\text { sensitivity }\end{array}$ & $\begin{array}{l}\text { Managerial heterogeneity likely to } \\
\text { influence subjective probabilities, } \\
\text { weightings, utilities and optimal } \\
\text { choices } \\
\text { Results in sensitivity to priming, framing, } \\
\text { and other biases attributed to subjective } \\
\text { individual decision-making under } \\
\text { ambiguity }\end{array}$ & $\begin{array}{l}\text { Firm reward system likely to mitigate } \\
\text { heterogeneity of rational managers } \\
\text { over optimal choices } \\
\text { Manager is bound to firm's policy (e.g., } \\
\text { maximin) and unweighted payoff } \\
\text { measures }\end{array}$ \\
\hline Predictability & $\begin{array}{l}\text { Unlikely; need to know manager's } \\
\text { probability weightings and utility } \\
\text { function (beliefs, biases, anchors and so } \\
\text { on, precisely) }\end{array}$ & $\begin{array}{l}\text { Likely; only need to know firm's } \\
\text { investment choices and reward system } \\
\text { (which is known is firm is publicly } \\
\text { traded) }\end{array}$ \\
\hline $\begin{array}{c}\text { Managerial } \\
\text { reward }\end{array}$ & $\begin{array}{l}\text { Based on what was known/believed } \\
\text { Rewarding success of guessing } \\
\text { based on outcomes }\end{array}$ & $\begin{array}{l}\text { Based on what was not known } \\
\text { Punishing failure to adhere to incentives } \\
\text { Based on consistency of outcomes }\end{array}$ \\
\hline $\begin{array}{l}\text { Source of firm } \\
\text { performance } \\
\text { variance }\end{array}$ & $\begin{array}{l}\text { Arising from manager heterogeneity (over } \\
\text { utility and probability functions) of firm } \\
\text { and rivals }\end{array}$ & $\begin{array}{l}\text { Expected homogeneity of incumbents, } \\
\text { with most variance arising from } \\
\text { extreme positions of entrepreneurs }\end{array}$ \\
\hline Main concerns & $\begin{array}{l}\text { Individual heterogeneity-over } \\
\text { probability predictions, weightings and } \\
\text { biases, some of which can be } \\
\text { manipulated }\end{array}$ & Efficiency frontier and reward system \\
\hline Strategic focus & On individual behavior, if any such focus & $\begin{array}{l}\text { Yes, accounting explicitly for } \\
\text { interdependencies and for competitive, } \\
\text { independent parties in the optimization }\end{array}$ \\
\hline
\end{tabular}

remains important for the strategy field to research; and, it may even embody an endeavor that provides the means to improve the core of how social scientific progress is made.

Funding This study was not funded.

\section{Compliance with ethical standards}

Conflict of interest The author (Arend) declares he has no conflicts of interest.

Ethical approval No human subjects nor animal participants were involved in this research. 
Open Access This article is licensed under a Creative Commons Attribution 4.0 International License, which permits use, sharing, adaptation, distribution and reproduction in any medium or format, as long as you give appropriate credit to the original author(s) and the source, provide a link to the Creative Commons licence, and indicate if changes were made. The images or other third party material in this article are included in the article's Creative Commons licence, unless indicated otherwise in a credit line to the material. If material is not included in the article's Creative Commons licence and your intended use is not permitted by statutory regulation or exceeds the permitted use, you will need to obtain permission directly from the copyright holder. To view a copy of this licence, visit http:// creativecommons.org/licenses/by/4.0/.

\section{References}

Bajtelsmit, V., J. Coats, and P. Thistle. 2015. The effect of ambiguity on risk management choices: An experimental study. Journal of Risk and Uncertainty 50 (3): 249-280.

Becker, S.W., and F. Brownson. 1964. What price ambiguity? Or the role of ambiguity in decision making. Journal of Political Economy 72: 62-73.

Bryant, W.D.A. 2014. The Microeconomics of choice under risk and uncertainty: where are we? Vikalpa 39 (1): $21-40$.

Budescu, D.V., K.M. Kuhn, K.M. Kramer, and T.R. Johnson. 2002. Modeling certainty equivalents for imprecise gambles. Organizational Behavior and Human Decision Processes 88 (2): 748-768.

Camerer, C., and M. Weber. 1992. Recent Developments in Modeling Preferences: Uncertainty and Ambiguity. Journal of Risk and Uncertainty 5 (4): 325-370.

Cerreia-Vioglio, S., F. Maccheroni, M. Marinacci, and L. Montrucchio. 2013. Ambiguity and robust statistics. Journal of Economic Theory 148 (3): 974-1049.

Cinelli, M. 2020. Ambiguity of network outcomes. Journal of Business Research. https://doi.org/10.1016/ j.jbusres.2020.02.031.

Curley, S.P., and J.F. Yates. 1985. The center and range of the probability interval as factors affecting ambiguity preferences. Organizational Behavior and Human Decision Processes 36: 273-287.

Curley, S.P., and J.F. Yates. 1989. An empirical evaluation of descriptive models of ambiguity reactions in choice situations. Journal of Mathematical Psychology 33 (4): 397-427.

Davis, J.P., K.M. Eisenhardt, and C.B. Bingham. 2009. Optimal structure, market dynamism, and the strategy of simple rules. Administrative Science Quarterly 54 (3): 413-452.

Dominiak, A., and P. Duersch. 2019. Interactive Ellsberg tasks: An experiment. Journal of Economic Behavior and Organization 161: 145-157.

Dyer, J.H., and H. Singh. 1998. The relational view: Cooperative strategy and sources of interorganizational competitive advantage. Academy of Management Review 23 (4): 660-679.

Eason, C.C., and M.J. Mazzei. 2019. Teaching and Doing Strategy as an Intentional Strategic Innovation Mindset. Journal of Strategic Innovation and Sustainability 14 (4): 26-43.

Eichberger, J., and A. Guerdjikova. 2013. Ambiguity, data and preferences for information-A casebased approach. Journal of Economic Theory 148 (4): 1433-1462.

Einhorn, H.J., and R.M. Hogarth. 1986. Decision making under ambiguity. The Journal of Business 59 (4): S225-S250.

Eisenhardt, K.M., and D.N. Sull. 2001. Strategy as Simple Rules. Harvard Business Review 79 (1): $106-116$.

Elbanna, S., and J. Child. 2007. The influence of decision, environmental and firm characteristics on the rationality of strategic decision-making. Journal of Management Studies 44 (4): 561-591.

Ellsberg, D. 1961. Risk, Ambiguity, and the Savage Axioms. Quarterly Journal of Economics 75 (4): 643-669.

Ellsberg, D. 1963. Reply. Quarterly Journal of Economics 77: 336-342.

Forbes, D.P. 2007. Reconsidering the Strategic Implications of Decision Comprehensiveness. Academy of Management Review 32 (2): 361-376.

Galaabaatar, T., and E. Karni. 2013. Subjective expected utility with incomplete preferences. Econometrica 81 (1): 255-284.

Gardenfors, P., and N.E. Sahlin. 1982. Unreliable probabilities, risk taking, and decision making. Synthese 53: 361-386.

Ghemawat, P. 1991. Commitment. New York: Simon and Schuster. 
Gilboa, I., and D. Schmeidler. 1989. Maxmin expected utility with non-unique prior. Journal of Mathematical Economics 18 (2): 141-153.

Gollier, C. 2014. Optimal insurance design of ambiguous risks. Economic Theory 57 (3): 555-576.

Hahn, T., L. Preuss, J. Pinkse, and F. Figge. 2014. Cognitive frames in corporate sustainability: Managerial sensemaking with paradoxical and business case frames. Academy of Management Review 39 (4): 463-487.

Heath, C., and A. Tversky. 1991. Preference and belief: Ambiguity and competence in choice under uncertainty. Journal of Risk and Uncertainty 4 (1): 5-28.

Hey, J.D., G. Lotito, and A. Maffioletti. 2010. The descriptive and predictive adequacy of theories of decision making under uncertainty/ambiguity. Journal of Risk and Uncertainty 41 (2): 81-111.

Jia, R., E. Furlong, S. Gao, L.R. Santos, and I. Levy. 2020. Learning about the Ellsberg Paradox reduces, but does not abolish, ambiguity aversion. PLOS ONE 15 (3): e0228782.

Joseph, J., and V. Gaba. 2015. The fog of feedback: Ambiguity and firm responses to multiple aspiration levels. Strategic Management Journal 36 (13): 1960-1978.

Kahneman, D., and A. Tversky. 1979. Prospect theory: An analysis of decision under risk. Econometrica 47: 263-291.

Knightian, F.H. 1921. Risk, uncertainty, and profit. Boston: Houghton Mifflin.

Langley, A., H. Mintzberg, P. Pitcher, E. Posada, and J. Saint-Macary. 1995. Opening up Decision Making: The View from the Black Stool. Organization Science 6 (3): 260-279.

Lant, T.K., and S.J. Mezias. 1990. Managing Discontinuous Change: a Simulation Study of Organizational Learning and Entrepreneurship. Strategic Management Journal 11 (4): 147-179.

Leiblein, M.J., J.J. Reuer, and T. Zenger. 2018. What Makes a Decision Strategic? Strategy Science 3 (4): $558-573$.

Lévárdy, V., and T.R. Browning. 2009. An adaptive process model to support product development project management. IEEE Transactions on Engineering Management 56 (4): 600-620.

Li, Z., G. Loomes, and G. Pogrebna. 2017. Attitudes to uncertainty in a strategic setting. The Economic Journal 127 (601): 809-826.

Machina, M.J. 2014. Ambiguity Aversion with Three or More Outcomes. American Economic Review 104 (12): 3814-3840.

Małecka, M. 2020. The normative decision theory in economics: a philosophy of science perspective. The case of the expected utility theory. Journal of Economic Methodology 27 (1): 36-50.

Markowitz, H.M. 1952. Portfolio Selection. The Journal of Finance. 7 (1): 77-91.

Marschak, J. 1975. Personal probabilities of probabilities. Theory and Decision 6: 121-153.

McGrath, R.G. 1999. Falling forward: Real options reasoning and entrepreneurial failure. Academy of Management Review 24 (1): 13-30.

Miller, K.D. 1993. Industry and Country Effects on Managers' Perceptions of Environmental Uncertainties. Journal of International Business Studies 24 (4): 693-714.

Newman, J.L. 2009. Building a creative high-performance R\&D culture. Research-Technology Management 52 (5): 21-31.

Paraschiv, C., and A. Shyti. 2016. Entrepreneurs Under Ambiguity: A Prospect Theory Perspective. In Decision Making in Behavioral Strategy, ed. T.K. Das, 25-47. Charlotte: Information Age Publishing.

Petkova, A.P., A. Wadhwa, Y. Xin, and S. Jain. 2014. Reputation and Decision Making Under Ambiguity: A Study of U.S. Venture Capital Firms' Investments in the Emerging Clean Energy Sector. Academy of Management Journal 57 (2): 422-448.

Peysakhovich, A., and U.R. Karmarkar. 2016. Asymmetric effects of favorable and unfavorable information on decision making under ambiguity. Management Science 62 (8): 2163-2178.

Peysakhovich, A., and J. Naecker. 2017. Using methods from machine learning to evaluate behavioral models of choice under risk and ambiguity. Journal of Economic Behavior and Organization 133: 373-384.

Pich, M.T., C.H. Loch, and A. De Meyer. 2002. On Uncertainty, Ambiguity, and Complexity in Project Management. Management Science 48 (8): 1008-1023.

Pike, J.C., P.J. Bateman, and B.S. Butler. 2018. Information from social networking sites: Context collapse and ambiguity in the hiring process. Information Systems Journal 28 (4): 729-758.

Porter, M.E. 1980. Competitive Strategy: Techniques for Analyzing Industries and Competitors. New York: Free Press.

Reed, R., and R.J. DeFillippi. 1990. Causal ambiguity, barriers to imitation, and sustainable competitive advantage. Academy of Management Review 15 (1): 88-102. 
Rindova, V., W.J. Ferrier, and R. Wiltbank. 2010. Value from gestalt: how sequences of competitive actions create advantage for firms in nascent markets. Strategic Management Journal 31 (13): 1474-1497.

Sautua, S.I. 2017. Does uncertainty cause inertia in decision making? An experimental study of the role of regret aversion and indecisiveness. Journal of Economic Behavior and Organization 136: 1-14.

Savage, L.J. 1954. The foundations of statistics. New York, NY: Wiley.

Schmeidler, D. 1989. Subjective probability and expected utility without additivity. Econometrica 57 (3): 571-587.

Shafer, G.A. 1976. A mathematical theory of evidence. Princeton: Princeton University Press.

Sillince, J., P. Jarzabkowski, and D. Shaw. 2012. Shaping Strategic Action Through the Rhetorical Construction and Exploitation of Ambiguity. Organization Science 23 (3): 630-650.

Srivastava, S.B. 2015. Intraorganizational Network Dynamics in Times of Ambiguity. Organization Science 26 (5): 1365-1380.

Starmer, C. 2000. Developments in Non-expected Utility Theory: The Hunt for a Descriptive Theory of Choice under Risk. Journal of Economic Literature 38 (2): 332-382.

Su, H.T., and Y.K. Tung. 2012. Minimax expected opportunity loss: a new criterion for risk-based decision making. The Engineering Economist 57 (4): 247-273.

Tadelis, S. 2002. Complexity, flexibility, and the make-or-buy decision. The American Economic Review 92 (2): 433-437.

Taleb, N.N. 2012. Antifragile: how to live in a world we don't understand, vol. 3. London: Allen Lane.

Tversky, A., and D. Kahneman. 1992. Advances in prospect theory: Cumulative representation of uncertainty. Journal of Risk and Uncertainty 5 (4): 297-323.

Wallsten, T.S., B.H. Forsyth, and D. Budescu. 1983. Stability and coherence of health experts' upper and lower subjective probabilities about dose-response functions. Organizational Behavior and Human Performance 31: 277-302.

Yates, J.F., and L.G. Zukowski. 1976. Characterization of ambiguity in decision making. Behavioral Science 21: 19-25.

Zadeh, L.A. 1978. Fuzzy sets as a basis for a theory of possibility. Fuzzy Sets and Systems 1: 3-28.

Zajac, E.J., and C.P. Olsen. 1993. From Transaction Cost to Transactional Value Analysis: Implications for the Study of Interorganizational Strategies. Journal of Management Studies 31 (1): 131-145.

Publisher's Note Springer Nature remains neutral with regard to jurisdictional claims in published maps and institutional affiliations. 